\title{
Cancer stem cell-related factors are associated with the efficacy of pre-operative chemoradiotherapy for locally advanced rectal cancer
}

\author{
KAZUAKI HIROISHI $^{1}$, MASAFUMI INOMATA ${ }^{1}$, KENJI KASHIMA ${ }^{2}$, KAZUHIRO YASUDA $^{1}$, \\ NORIO SHIRAISHI $^{1}$, SHIGEO YOKOYAMA ${ }^{2}$ and SEIGO KITANO ${ }^{1}$ \\ Departments of ${ }^{1}$ Surgery I and ${ }^{2}$ Diagnostic Pathology, Oita University Faculty of Medicine, Oita 879-5593, Japan
}

Received February 2, 2011; Accepted March 18, 2011

DOI: $10.3892 /$ etm.2011.243

\begin{abstract}
Pre-operative chemoradiotherapy (CRT) is an important neoadjuvant therapy for locally advanced rectal cancer. In the present study, we investigated the factors that influence the efficacy of pre-operative CRT in locally advanced rectal cancer. We divided 50 patients with locally advanced rectal carcinoma treated with pre-operative CRT into two groups according to the grade of tumor response to pre-operative CRT: low-sensitivity group and high-sensitivity group. As candidates for the prediction of sensitivity to preoperative CRT, clinicopathological factors and 12 biomarkers, including factors related to tumor growth, cell cycle, apoptosis, tumor stroma and cancer stem cells, were examined immunohistochemically in 48 resected specimens. Thirty-one tumors showed high sensitivity and 19 showed low sensitivity to pre-operative CRT. The status of stem cell-related factors, CD133 and CD24, was significantly associated respectively with sensitivity to pre-operative $\mathrm{CRT}(\mathrm{P}=0.003, \mathrm{P}=0.029)$. In 10 tumors positive for both CD133 and CD24, low sensitivity to CRT was found in $9(90 \%)$, whereas in 16 tumors negative for both CD133 and CD24, low sensitivity was found in 3 (19\%). Other pathological parameters were not associated with tumor response to pre-operative CRT. In conclusion, overexpression of cancer stem cell-related factors, CD133 and CD24, is associated with the sensitivity of locally advanced rectal cancer to pre-operative CRT.
\end{abstract}

\section{Introduction}

Colorectal cancer is a leading cause of morbidity and mortality in developed countries (1). In Japan, an increasingly Westernized diet has led to a high incidence of colorectal

Correspondence to: Dr Kazuaki Hiroishi, Department of Surgery I, Oita University Faculty of Medicine, 1-1 Idaigaoka, Hasama-machi, Yufu, Oita 879-5593, Japan

E-mail: m07d5009@med.oita-u.ac.jp

Key words: rectal cancer, pre-operative chemoradiotherapy, cancer stem cell, CD133, CD24 cancer. Patients with rectal cancers are known to have an increased rate of local recurrence and decreased survival time compared to patients with tumors of the colon, a result due primarily to the surgical constraints imposed by the location of the rectum within the pelvis (2).

Pre-operative chemoradiotherapy (CRT) is a neoadjuvant therapy for locally advanced rectal cancer that reduces the incidence of local recurrence and improves survival (3). Therefore, CRT is widely used in many countries of the world. However, several tumors show a marked response to CRT, whereas others do not. Furthermore, several adverse events related to CRT, such as enteritis, anorexia, cardiac/ thromboembolic events, radiation dermatitis and hematologic toxicity, were reported to occur at frequencies of 6-43\% (4). Thus, pre-operative indicators of chemoradiosensitivity are required to avoid unnecessary application of pre-operative CRT, yet little is known about potential biological markers that may be associated with response to pre-operative CRT.

Recently, the discovery of rare subpopulations of cancer stem cells has created a new focus in cancer research. The heterogeneity of tumors can be explained by the concept of cancer stem cells supported by anti-apoptotic signaling. There are a few reports on cancer stem cells related to chemoradiation resistance $(5,6)$. Therefore, in this study we investigated the factors, including cancer stem cell-related factors, that influence the sensitivity of locally advanced rectal cancer to pre-operative CRT using surgical resected specimens to consider tumor heterogeneity.

\section{Materials and methods}

Patients. A total of 50 patients with locally advanced rectal carcinoma were treated with pre-operative CRT and surgical resection at the Department of Surgery I, Oita University Faculty of Medicine, or associated institutions (Beppu Medical Center, Nakatsu Municipal Hospital, Oita Prefectural Hospital and Nankai Hospital) between January 2000 and May 2010. Tumors were located at the middle or lower third of the rectum and were diagnosed as clinical stage T2, T3 or T4, Nx and M0 (UICC TNM Classification of Malignant Tumours, 2009). T stage was determined by computed tomography (CT) scan or endoscopic ultrasonography. No 
distant metastases were detected on plain chest X-rays or CT scans. Thirty-nine patients were treated with pre-operative CRT and another 11 patients were treated with pre-operative radiotherapy (RT) alone. The total dose of radiation in most cases was 45 Gy within 6 weeks, usually 1.5 Gy per treatment, five times per week. The total dose range was 40-50 Gy. Several chemotherapy regimens were used in the patients treated with CRT: TS- $1\left(80 \mathrm{mg} / \mathrm{m}^{2}\right)$ in 21 patients, 5-fluorouracil (5-FU)-based in 5 patients, tegafur/uracil (UFT) and leucovorin or UFT alone in 8 patients, and tegafur in 5 patients. Curative surgery that included total mesorectal excision was performed in all patients after an interval of approximately 4 weeks following completion of pre-operative treatment. Patient informed consent and approval of the local ethics committee was obtained prior to the study.

Immunohistochemistry. A total of 12 biomarkers were chosen as candidate predictive factors for the efficacy of pre-operative CRT (7-13). These factors included tumor growth-related factors, epidermal growth factor receptor (EGFR) and human epidermal growth factor receptor-2 (HER2); cell cycle-related factors, p53, p21, Ki-67 and Bcl-1; apoptosis-related factors, Bcl-2 and apoptosis protease-activating factor-1 (APAF-1); tumor stroma-related factors, vascular endothelial growth factor (VEGF) and macrophage migration inhibitory factor (MIF); and cancer stem cell (tumor initiating cell)-related factors, CD133 and CD24. Postoperative resected specimens were used for immunohistochemistry.

Paraffin-embedded sections of tumor tissue from the resected rectum were cut at a thickness of $4 \mu \mathrm{m}$, deparaffinized in xylene and rehydrated. Endogenous peroxidase activity was blocked with $3 \%$ hydrogen peroxidase for $10 \mathrm{~min}$. For antigen retrieval, sections were autoclaved at $121^{\circ} \mathrm{C}$ in $10 \mathrm{mM}$

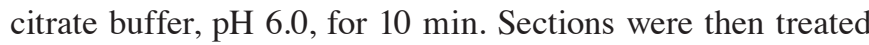
with primary antibodies. Immunostaining was performed by the avidin-biotin-peroxidase complex technique using a Histofine SAB-PO (Multi) kit (Nichirei Co., Tokyo, Japan) and diaminobenzidine for the visualization of the binding antibodies (14). The following primary antibodies were used: EGFR (clone EGFR113, 1:100; Lab Vision Inc., Fremont, CA, USA) (15); p53 (clone DO-7, 1:50; DakoCytomation, Glostrup, Denmark); p21 (clone SX118, 1:40; DakoCytomation); Ki-67 (clone MIB-1, 1:50; DakoCytomation); Bcl-1 (clone SP4; Nichirei Co.) (16); Bcl-2 (clone 124, 1:40; DakoCytomation); APAF-1 (NCL-APAF-1, 1:20; Novocastra, Newcastle, UK) (17); VEGF (VEGF A-20, 1:100; Santa Cruz Biotechnology, Santa Cruz, CA, USA) (18); MIF (FL-115, 1:200; Santa Cruz Biotechnology) (13); CD133 (ab19898, 1:200; Abcam, Tokyo, Japan) (19); and CD24 (clone SN3b, 1:100; Lab Vision Inc.) (20). Immunohistochemistry for HER2 was performed with HercepTest (DakoCytomation) (21). Negative controls were treated identically, omitting the primary antibodies. Tumor positivity for a given marker was evaluated using a predetermined cut-off of $10 \%$ (the average of the percentage of tumor cells stained in five fields at x100 magnification: $\leq 10 \%$ tumor cell staining, negative; $>10 \%$, positive) according to previous studies $(7,8,22)$. For Ki-67 immunoreactivity, staining was considered positive at $>60 \%$ (23). Staining was assessed in the nucleus for p53, p21, Ki-67 and Bcl-1, and in the cytoplasm for EGFR, APAF-1, VEGF, MIF, CD133 and
Table I. Patient and treatment characteristics.

\begin{tabular}{|c|c|c|}
\hline Characteristic & $\begin{array}{l}\text { No. of patients } \\
(\mathrm{n}=50)\end{array}$ & $\%$ \\
\hline \multicolumn{3}{|l|}{ Age (years) } \\
\hline Median & 64 & \\
\hline Range & $40-83$ & \\
\hline \multicolumn{3}{|l|}{ Gender } \\
\hline Male & 37 & 74 \\
\hline Female & 13 & 26 \\
\hline \multicolumn{3}{|l|}{ Surgery } \\
\hline Total pelvic exenteration & 1 & 14 \\
\hline Abdominoperineal resection & 24 & 48 \\
\hline Sphincter-preserving operation & 19 & 38 \\
\hline \multicolumn{3}{|l|}{ Macropathology } \\
\hline Circumscribed & 41 & 82 \\
\hline Infiltrative & 9 & 18 \\
\hline \multicolumn{3}{|l|}{ Histology $\mathrm{y}^{\mathrm{a}}$} \\
\hline Well differentiated & 9 & 19 \\
\hline Moderately differentiated & 31 & 66 \\
\hline Poorly differentiated & 3 & 6 \\
\hline Mucinous & 4 & 9 \\
\hline \multicolumn{3}{|l|}{ T-category ${ }^{\mathrm{a}}$} \\
\hline pT1 & 2 & 4 \\
\hline pT2 & 8 & 17 \\
\hline pT3 & 27 & 57 \\
\hline pT4 & 10 & 21 \\
\hline \multicolumn{3}{|l|}{ N-category } \\
\hline pN0 & 38 & 76 \\
\hline $\mathrm{pN}^{+}$ & 12 & 24 \\
\hline \multicolumn{3}{|l|}{ Vessel invasion } \\
\hline Negative & 25 & 50 \\
\hline Positive & 25 & 50 \\
\hline \multicolumn{3}{|l|}{ Tumor response (CRT sensitivity) } \\
\hline High sensitivity & 31 & 62 \\
\hline Low sensitivity & 19 & 38 \\
\hline
\end{tabular}

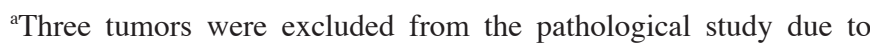
complete pathologic tumor regression. CRT, chemoradiotherapy.

CD24. Immunoreactivity for Bcl-2 and HER2 expression was assessed in both the cytoplasm and/or the cell membrane. Staining intensity was not evaluated.

Classification of response to pre-operative CRT. Tumor response to pre-operative CRT was evaluated pathologically on postoperative specimens according to the evaluation of the standard of therapeutic effect provided in the General Rules for Clinical and Pathological Studies on Cancer of the Colon, Rectum and Anus edited by the Japanese Society for Cancer of the Colon and Rectum (24). According to these standards, evaluation of the therapeutic effect was categorized according to five grades: grade 0 , absence of regressive changes; grade 1a, regressive change of tumor $<1 / 3$; grade $1 \mathrm{~b}$, regressive change of 

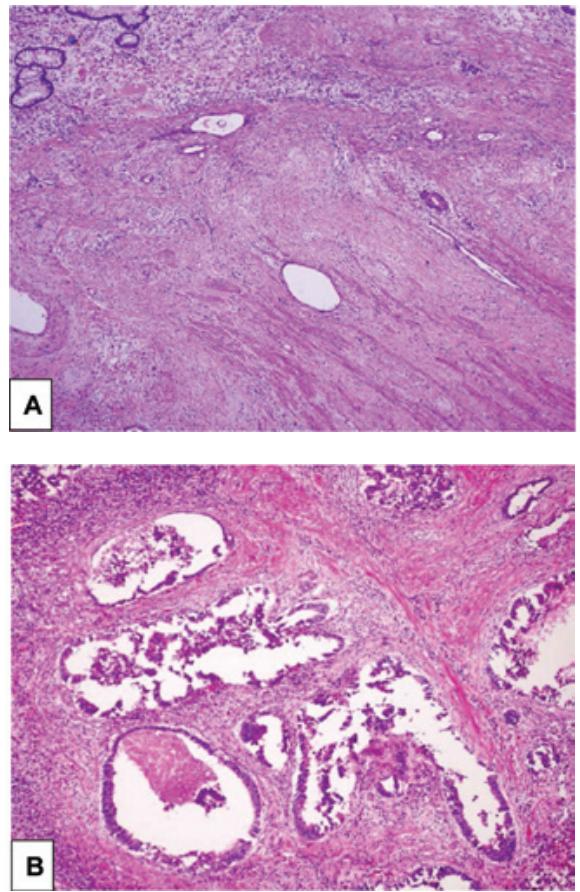

Figure 1. Photomicrographs indicating classification of the pathological response of pre-operative CRT in rectal cancer. (A) High-sensitivity case in which most tumor cells are replaced by fibrosis accompanying the infiltration of inflammatory cells (H\&E stain; original magnification, x40). (B) Lowsensitivity case in which most tumor cells remain with mild tumor necrosis and regressive change (H\&E stain; original magnification, $\mathrm{x} 40$ )

tumor $<2 / 3$; grade 2 , regressive change of tumor $>2 / 3$; grade 3 , absence of residual tumor cells. We considered grades 0 or $1 \mathrm{a}$ to indicate low sensitivity and grades $1 b, 2$ or 3 to indicate high sensitivity to pre-operative CRT (Fig. 1).

Statistical analysis. For statistical comparisons of patient characteristics between the two groups (low sensitivity and high sensitivity), the Chi-square test, the Fisher's exact probability test or the unpaired t-test was used. A value of $\mathrm{P}<0.05$ was considered statistically significant. All analyses were performed with SPSS Software (version 11.0) (SPSS Japan Inc., Tokyo, Japan).

\section{Results}

Patient and tumor characteristics. There were 37 (74\%) men and $13(26 \%)$ women included in the study. The median age was 64 years (range 40-83). Abdominoperineal resection was performed in 24 (48\%) patients and a sphincter-preserving operation was performed in 19 (38\%) patients. Macroscopic findings showed $82 \%$ of the tumors to be circumscribed tumors and, histologically, most $(85 \%)$ of the tumors were of the well or moderately differentiated type. Lymph node metastasis was observed in $12(24 \%)$ patients. Vessel invasion was observed in $25(50 \%)$ patients. On the basis of the classification of responses to pre-operative CRT, 31 tumors showed high sensitivity and 19 tumors showed low sensitivity to pre-operative CRT (Table I).

Status of response to CRT according to various clinical parameters. Gender, age, macropathology, location, histology,
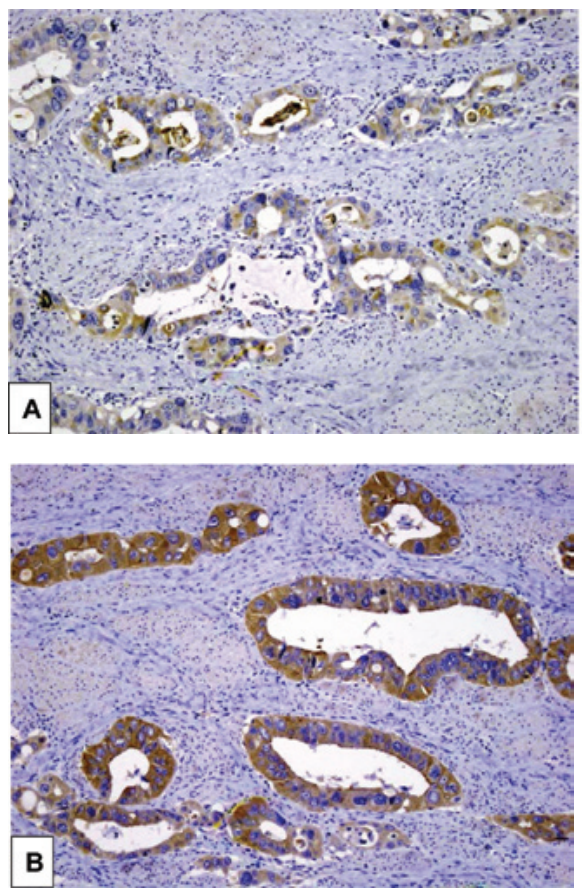

Figure 2. Photomicrographs showing immunohistochemical staining of CD133 and CD24 in rectal carcinoma. (A) Cytoplasmic expression of CD133 in tumor cells is observed (original magnification, $\mathrm{x} 200$ ). Glioblastoma tissue sections were used as a positive control. (B) Strong cytoplasmic expression of CD24 in tumor cells is observed (original magnification, x200). Ovarian serous adenocarcinoma tissue sections were used as a positive control.

$\mathrm{N}$-category and surgery were not associated with tumor response (Table II). Of the 10 patients with pT1-2 tumors, 9 showed high sensitivity. The number of pT3-4 tumors showing high sensitivity was nearly equal to those showing low sensitivity $(\mathrm{P}=0.034)$. Of the tumors negative for vessel invasion, 21 of 25 showed high sensitivity, whereas 15 of 25 tumors positive for vessel invasion showed low sensitivity $(\mathrm{P}=0.003)$.

Response rates according to various pathological parameters. Factors related to tumor growth, the cell cycle, apoptosis and tumor stroma were not associated with tumor response (Table III). Only factors related to cancer stem cells (tumorinitiating cells) were associated with tumor response. A significant association was found between the resistance of the tumor to treatment and negative CD133 status $(\mathrm{P}=0.003)$, and there was a significant statistical correlation between the resistance of the tumor to treatment and positive CD24 status $(\mathrm{P}=0.029)$. In the high-sensitivity tumors, 3 tumors that had complete pathologic tumor regression were excluded from the pathological study (histology and T-category in Tables I and II) and immunohistochemical analysis since the resected specimens did not contain cancer cells (Fig. 2).

Response rates based on combinations of CD133 and CD24. When both CD133 and CD24 were positive, 9 of $10(90 \%)$ tumors showed low sensitivity, whereas when both CD133 and CD24 were negative, 3 of 16 (19\%) tumors showed low sensitivity (Table IV). Co-overexpression of CD133 and CD24 was associated with low sensitivity $\left(\mathrm{CD} 133^{+}\right.$and $\mathrm{CD} 24^{+}$vs. others, $\mathrm{P}=0.001)$. Negative expression of both CD133 and 
Table II. Response according to various clinical parameters.

\begin{tabular}{|c|c|c|c|}
\hline Parameter & High sensitivity $(\mathrm{n}=31)$ & Low sensitivity $(\mathrm{n}=19)$ & P-value \\
\hline Gender & & & 0.481 \\
\hline Male & 24 & 13 & \\
\hline Female & 7 & 6 & \\
\hline Age (years) & & & 0.635 \\
\hline Median & 64 & 65 & \\
\hline Range & $44-82$ & $40-83$ & \\
\hline Macropathology & & & 0.715 \\
\hline Circumscribed & 26 & 15 & \\
\hline Infiltrative & 5 & 4 & \\
\hline Location & & & 0.273 \\
\hline Upper & 4 & 5 & \\
\hline Lower & 27 & 14 & \\
\hline Histology $\mathrm{a}^{\mathrm{a}}$ & & & 0.102 \\
\hline Well/moderate differentiation & 26 & 14 & \\
\hline Poor/mucinous differentiation & 2 & 5 & \\
\hline T-category ${ }^{\mathrm{a}}$ & & & 0.034 \\
\hline $\mathrm{pT} 1 / 2$ & 9 & 1 & \\
\hline pT3/4 & 19 & 18 & \\
\hline $\mathrm{N}$-category & & & 0.764 \\
\hline pNO & 24 & 14 & \\
\hline $\mathrm{pN} 1,2$ & 7 & 5 & \\
\hline Vessel invasion & & & 0.003 \\
\hline Negative & 21 & 4 & \\
\hline Positive & 10 & 15 & \\
\hline Surgery & & & 0.464 \\
\hline LAR/Lap. LAR & 13 & 6 & \\
\hline APR/Lap. APR & 18 & 13 & \\
\hline
\end{tabular}

${ }^{a}$ Three tumors were excluded from pathologic study due to complete pathologic tumor regression. APR, abdominoperineal resection (including total pelvic exenteration); Lap., laparoscopic; LAR, low anterior resection (including sphincter-preserving operation).

CD24 was associated with high sensitivity (CD133 and CD24 vs. others, $\mathrm{P}=0.030$ ).

\section{Discussion}

The present study demonstrated that co-overexpression of cancer stem cell-related factors, CD133 and CD24, was significantly associated with locally advanced rectal cancer exhibiting low sensitivity to pre-operative CRT. This result suggests that these two biomarkers may influence sensitivity to pre-operative CRT.

In this study, we used resected specimens from patients who had been treated with pre-operative CRT. For identifying factors which predict the efficacy of CRT before treatment, the use of pre-treatment biopsy specimens is advisable. However, there is heterogeneity in the tumor (5). Therefore, biopsy specimens were not used, and resected specimens were used to investigate the entire tumor specimen.

For the evaluation of CD133 and CD24 expression, immunostaining was classified using the $10 \%$ cut-off scoring system. Although one report set the cut-off value to $50 \%$, we adopted the standard system as it has been widely used in many studies. Expression of CD133 and CD24 was distributed evenly within the resected tumors. In the localization of staining, membranous expression of CD24 without cytoplasmic positivity was detected, but we did not include it as being indicative of positive expression.

The concept of cancer stem cells which has been proposed in the field of blood cancer (25) has been adjusted to address solid tumors, such as those of colorectal cancer (26). The fundamental cancer stem cell concept assumes that cancer cells exhibit a hierarchy, as do normal cells, and that a small fraction of cancer cells are maintained as 'cancer stem cells', which have the ability of self-renewal and differentiation (27). Cancer stem cells have recently been proposed to be the cancer-initiating cells that are responsible for tumorigenesis and for contributing to drug resistance in cancer (28). Although a comparatively large number of studies have been reported concerning cancer stem cells and resistance to either chemotherapy or radiotherapy in various cancers, there are few studies available concerning cancer stem cells and resistance to CRT (5). 
Table III. Response according to various pathological parameters.

\begin{tabular}{|c|c|c|c|}
\hline Biomarker & $\begin{array}{l}\text { High sensitivity } \\
\qquad(\mathrm{n}=28)\end{array}$ & $\begin{array}{l}\text { Low sensitivity } \\
\qquad(\mathrm{n}=19)\end{array}$ & P-value \\
\hline HER 2 & & & 1.000 \\
\hline+ & 1 & 0 & \\
\hline- & 27 & 19 & \\
\hline EGFR & & & 0.453 \\
\hline+ & 4 & 5 & \\
\hline- & 24 & 14 & \\
\hline VEGF & & & 0.119 \\
\hline+ & 21 & 18 & \\
\hline- & 7 & 1 & \\
\hline MIF & & & 0.770 \\
\hline+ & 13 & 8 & \\
\hline- & 15 & 11 & \\
\hline p53 & & & 0.137 \\
\hline+ & 24 & 19 & \\
\hline- & 4 & 0 & \\
\hline p21 & & & 0.143 \\
\hline+ & 5 & 7 & \\
\hline- & 23 & 12 & \\
\hline $\mathrm{Ki}-67$ & & & 0.739 \\
\hline+ & 19 & 12 & \\
\hline- & 9 & 7 & \\
\hline Bcl-1 & & & 1.000 \\
\hline+ & 7 & 4 & \\
\hline- & 21 & 15 & \\
\hline Bcl-2 & & & 0.435 \\
\hline+ & 16 & 13 & \\
\hline- & 12 & 6 & \\
\hline APAF-1 & & & 0.119 \\
\hline+ & 21 & 18 & \\
\hline- & 7 & 1 & \\
\hline CD133 & & & 0.003 \\
\hline+ & 2 & 9 & \\
\hline- & 26 & 10 & \\
\hline CD24 & & & 0.029 \\
\hline+ & 14 & 16 & \\
\hline- & 14 & 3 & \\
\hline
\end{tabular}

+ , positive expression; -, negative expression.

CD133 and CD24 have been reported as cancer stem cell markers of colorectal cancer in previous studies $(26,29,30)$. CD133 is a 5-transmembrane glycoprotein of 865 amino acids with a total molecular weight of $120 \mathrm{kDa}$. CD133 antigen expression has been found in such various undifferentiated cells as hematopoietic stem cells (31) and fetal brain stem cells (32). In cancer cells, CD133 has been found to be expressed on cancer stem or tumor-initiating cells in cancers, such as leukemia (33), brain tumors (34) and colorectal cancer. CD24 consists of a small protein core comprising 27 amino acids, which is extensively glycosylated and is bound
Table IV. Response according to combinations of CD133 and CD24.

\begin{tabular}{|c|c|c|c|c|}
\hline \multirow[t]{2}{*}{ Case } & \multicolumn{2}{|c|}{$\begin{array}{l}\text { High sensitivity } \\
\qquad(\mathrm{n}=28)\end{array}$} & \multicolumn{2}{|c|}{$\begin{array}{l}\text { Low sensitivity } \\
\qquad(\mathrm{n}=19)\end{array}$} \\
\hline & No. & $\%$ & No. & $\%$ \\
\hline $\mathrm{CD}_{133}{ }^{+}$and $\mathrm{CD} 24^{+\mathrm{a}}$ & 1 & 10 & 9 & 90 \\
\hline $\mathrm{CD}_{133^{+}}$and $\mathrm{CD} 24^{-}$ & 1 & 100 & 0 & 0 \\
\hline $\mathrm{CD}_{133^{-}}$and $\mathrm{CD} 24^{+}$ & 13 & 65 & 7 & 35 \\
\hline CD133 $3^{-}$and $24^{-b}$ & 13 & 81 & 3 & 19 \\
\hline
\end{tabular}

${ }^{\mathrm{a}}\left(\mathrm{CD} 133^{+}\right.$and $\left.\mathrm{CD} 24^{+}\right)$vs. others, $\mathrm{P}=0.001 .^{\mathrm{b}}\left(\mathrm{CD} 133^{-}\right.$and $\left.\mathrm{CD} 24^{-}\right)$vs. others, $\mathrm{P}=0.030$.

to the cell membrane via a phosphatidylinositol anchor (35). Several reports have shown that CD24 is expressed in several solid tumors, such as those of small-cell lung cancer and neuroblastoma $(36,37)$, but not in those of colorectal cancer.

Recently, positive clinical studies on the effectiveness of pre-operative CRT on locally advanced rectal cancer have been reported (38). However, pre-operative CRT is not effective in all cases and, actually, cases in which no antineoplastic effect was obtained also exist. Since the treatment period for pre-operative CRT is approximately 10 weeks, patients who obtain no response to CRT lose valuable time during which they could have been treated more effectively. Thus, it is necessary to investigate factors which influence the efficacy of pre-operative CRT.

The results of the present study suggest that the presence of CD133 and CD24 expression is associated with the efficacy of pre-operative CRT. Assuming that CD133 and CD24 are predictive factors of the sensitivity to pre-operative CRT, patients with both $\mathrm{CD} 133^{+}$and $\mathrm{CD} 24^{+}$are expected to have low sensitivity to CRT. So, it may be recommended that such patients undergo surgery without first undergoing CRT. However, since patients with both $\mathrm{CD}_{133^{-}}$and $\mathrm{CD} 24^{-}$are expected to have high sensitivity to CRT, it may be necessary to aggressively treat these patients first with pre-operative CRT.

In conclusion, the present study shows that the overexpression of cancer stem cell-related factors, CD133 and CD24, is associated with the sensitivity of locally advanced rectal cancer to pre-operative CRT. Further prospective studies are required to establish a new therapeutic system that appropriately uses pre-operative CRT for the benefit of patients with locally advanced rectal cancer. Our group is presently conducting a prospective study using biopsy specimens from pre-therapeutic tumors (UMIN003398). This retrospective study provides valuable information for realization of the ongoing prospective study.

\section{Acknowledgements}

The authors thank Dr Koshi Mimori (Department of Surgery and Molecular Oncology, Medical Institute of Bioregulation, Kyushu University); Dr Yoichi Muto, Dr Tetsuya Kusumoto and Dr Toshifumi Matsumoto (Department of Surgery, Beppu 
Medical Center); Dr Masahito Ikeda, Dr Fumiaki Kishihara and Dr Akio Shiromizu (Department of Surgery, Nakatsu Municipal Hospital); Dr Hisanobu Sakata and Dr Kyuzo Fujii (Department of Surgery, Oita Prefectural Hospital); Dr Takayuki Kamegawa and Dr Akio Morimoto (Department of Surgery, Nankai Hospital); and Dr Akira Matsumoto (Department of Radiology, Oita University Faculty of Medicine) for their invaluable assistance in this study. They also thank Nagako Katsuki, Mayumi Takeda, Emi Aono and Tomoka Sato for the excellent technical support.

\section{References}

1. Jemal A, Siegel R, Ward E, et al: Cancer statistics, 2006. CA Cancer J Clin 56: 106-130, 2006.

2. Wolpin BM, Meyerhardt JA, Mamon HJ and Mayer RJ: Adjuvant treatment of colorectal cancer. CA Cancer J Clin 57: 168-185, 2007.

3. Sauer R, Becker H, Hohenberger W, et al: Pre-operative versus postoperative chemoradiotherapy for rectal cancer. N Engl J Med 351: 1731-1740, 2004.

4. Calvo FA, Serrano FJ, Diaz-González JA, et al: Improved incidence of pT0 downstaged surgical specimens in locally advanced rectal cancer (LARC) treated with induction oxaliplatin plus 5-fluorouracil and pre-operative chemoradiation. Ann Oncol 17: 1103-1110, 2006.

5. Ishii H, Iwatsuki M, Ieta K, et al: Cancer stem cells and chemoradiation resistance. Cancer Sci 99: 1871-1877, 2008.

6. Haraguchi N, Inoue H, Tanaka F, et al: Cancer stem cells in human gastrointestinal cancers. Hum Cell 19: 24-29, 2006.

7. Zlobec I, Vuong T and Compton CC: The predictive value of apoptosis protease-activating factor 1 in rectal tumors treated with pre-operative, high-dose-rate brachytherapy. Cancer 106 : 284-286, 2005.

8. Negri FV, Campanini N, Camisa R, et al: Biological predictive factors in rectal cancer treated with pre-operative radiotherapy or radiochemotherapy. Br J Cancer 98: 143-147, 2008.

9. Zlobec I, Vuong T, Compton CC, et al: Combined analysis of VEGF and EGFR predicts complete tumour response in rectal cancer treated with pre-operative radiotherapy. Br J Cancer 98 450-456, 2008

10. Horst D, Kriegl L, Engel J, Kirchner T and Jung A: CD133 expression is an independent prognostic marker for low surviva in colorectal cancer. Br J Cancer 99: 1285-1289, 2008.

11. Haraguchi N, Ohkuma M, Sakashita H, et al: $\mathrm{CD} 133^{+} \mathrm{CD} 24^{+}$ population efficiently enriches colon cancer initiating cells. Ann Surg Oncol 15: 2927-2933, 2008.

12. Choi D, Lee HW, Hur KY, et al: Cancer stem cell markers CD133 and CD24 correlate with invasiveness and differentiation in colorectal adenocarcinoma. World J Gastroenterol 15: 2258-2264, 2009.

13. He XX, Chen K, Yang J, et al: Macrophage migration inhibitory factor promotes colorectal cancer. Mol Med 15: 1-10, 2009.

14. Tanahashi J, Daa T, Gamachi A, et al: Human intestinal spirochetosis in Japan; its incidence, clinicopathologic features, and genotypic identification. Mod Pathol 21: 76-84, 2008.

15. Sato JD, Kawamoto T, Le AD, Mendelsohn J, Polikoff J and Sato GH: Biological effects in vitro of monoclonal antibodies to human epidermal growth factor receptors. Mol Biol Med 1: 511-529, 1983.

16. Cheuk W, Wong KO, Wong CS and Chan JK: Consistent immunostaining for cyclin D1 can be achieved on a routine basis using a newly available rabbit monoclonal antibody. Am J Surg Pathol 28: 801-807, 2004

17. Paik SS, Jang KS, Song YS, et al: Reduced expression of Apaf-1 in colorectal carcinoma correlates with tumor progression and aggressive phenotype. Ann Surg Oncol 14: 3453-3459, 2007.

18. Rosmorduc O, Wendum D, Corpechot C, et al: Hepatocellular hypoxia-induced vascular endothelial growth factor expression and angiogenesis in experimental biliary cirrhosis. Am J Pathol 155: 1065-1073, 1999.
19. Dubrovska A, Kim S, Salamone RJ, et al: The role of PTEN/ $\mathrm{Akt} / \mathrm{PI} 3 \mathrm{~K}$ signaling in the maintenance and viability of prostate cancer stem-like cell populations. Proc Natl Acad Sci USA 106: 268-273, 2009.

20. Kim KH, Choi JS, Kim JM, et al: Enhanced CD24 expression in endometrial carcinoma and its expression pattern in normal and hyperplastic endometrium. Histol Histopathol 24: 309-316, 2009.

21. Press MF, Hung G, Godolphin W and Slamon DJ: Sensitivity of HER-2/neu antibodies in archival tissue samples: potential source of error in immunohistochemical studies of oncogene expression. Cancer Res 54: 2771-2777, 1994.

22. Yada K, Shibata K, Matsumoto T, Ohta M, Yokoyama S and Kitano S: Protease-activated receptor-2 regulates cell proliferation and enhances cyclooxygenase- 2 mRNA expression in human pancreatic cancer cells. J Surg Oncol 89: 79-85, 2005.

23. Sadahiro S, Suzuki T, Maeda Y, et al: Predictors of tumor downsizing and regression with pre-operative radiotherapy alone and with concomitant tegafur/uracil (UFT) for resectable advanced rectal adenocarcinoma. Hepatogastroenterology 54: 1107-1112, 2007.

24. Japanese Society for Cancer of the Colon and Rectum: General Rules for Clinical and Pathological Studies on Cancer of the Colon, Rectum and Anus: The 7th edition, revised version. Tokyo, Kanehara, 2009.

25. Lapidot T, Sirard C, Vormoor J, et al: A cell initiating human acute myeloid leukaemia after transplantation into SCID mice. Nature 367: 645-648, 1994.

26. Ricci-Vitiani L, Lombardi DG, Pilozzi E, et al: Identification and expansion of human colon-cancer-initiating cells. Nature 445: 111-115, 2007.

27. Reya T, Morrison SJ, Clarke MF and Weissman IL: Stem cells, cancer, and cancer stem cells. Nature 414: 105-111, 2001.

28. Jordan CT, Guzman ML and Noble M: Cancer stem cells. N Engl J Med 355: 1253-1261, 2006.

29. Ieta K, Tanaka F, Haraguchi N, et al: Biological and genetic characteristics of tumor-initiating cells in colon cancer. Ann Surg Oncol 15: 638-648, 2008.

30. Weichert W, Denkert C, Burkhardt M, et al: Cytoplasmic CD24 expression in colorectal cancer independently correlates with shortened patient survival. Clin Cancer Res 11: 6574-6581, 2005.

31. Yin AH, Miraglia S, Zanjani ED, et al: AC133, a novel marker for human hematopoietic stem and progenitor cells. Blood 90: 5002-5012, 1997.

32. Uchida N, Buck DW, He D, et al: Direct isolation of human central nervous system stem cells. Proc Natl Acad Sci USA 97: 14720-14725, 2000.

33. Bhatia M: AC133 expression in human stem cells. Leukemia 15: 1685-1688, 2001.

34. Singh SK, Clarke ID, Terasaki M, et al: Identification of a cancer stem cell in human brain tumors. Cancer Res 63: 5821-5828, 2003.

35. Fischer GF, Majdic O, Gadd S and Knapp W: Signal transduction in lymphocytic and myeloid cells via CD24, a new member of the phosphoinositol-anchored membrane molecules. J Immunol 144: 638-641, 1990.

36. Jackson D, Waibel R, Weber E, Bell J and Stahel RA: CD24, a signal-transducing molecule expressed on human B cells, is a major surface antigen in small-cell lung carcinomas. Cancer Res 52: 5264-5270, 1992.

37. Akashi T, Shirasawa T and Hirokawa K: Gene expression of CD24 core polypeptide molecule in normal rat tissues and human tumor cell lines. Virchows Arch 425: 399-406, 1994.

38. Roh MS, Colangelo LH, O'Connell MJ, et al: Pre-operative multimodality therapy improves disease-free survival in patients with carcinoma of the rectum: NSABP R-03. J Clin Oncol 27: 5124-5130, 2009 